\title{
The use of creative techniques in the engineering human resources development
}

\author{
Claudiu Pirnau*, Daniel Ghiculescu, and Ion Niculae Marinescu \\ Politehnica University of Bucharest, 313 Splaiul Independentei, sector 6, Bucharest, Romania
}

\begin{abstract}
Starting from the role of new technologies in the development of engineering innovation, this paperwork has two main research directions with respect to creativity and innovation in engineering education. These are based on a combination of creative techniques with traditional engineering education methods. The first component of our research presented herein aims the use of creative methods such as Creative Training and Image Streaming, and the second component of the research statistically analyses the Social Media posts regarding the use of Cloud Computing technology as a support for innovation. The aim of combining such lines of research will lead to the emergence of specific knowledge needed to identify and implement new creative techniques in engineering human resources. Applying such creativity techniques within groups of students can result in innovative ideas usable in ongoing research projects, in certain deadlock situations on finding critical solutions to overcome blockages.
\end{abstract}

\section{Introduction}

The future engineers' education is based on two fundamental factors: creativity and innovation [1]. The parameters needed in developing the creativity and the innovation can be analyzed from two perspectives: the individual who learns (intellectual capital) and the creative community (Creative \& Connected Community, Creative Bio - Community etc.) [23]. The introduction of ECED diagrams (Engineering Creativity Enterprise Diagram) reflects the degree of industrialization and the technological level of any community, correlated with the one of creativity and innovation [4]. This approach can result in courses and specific activities, which would increase the creative and innovative skills and capacities of the future engineers.

This paperwork arose from the need to improve the students' ability with respect to the long term creative thinking, thus contributing to the improvement of the future industrial products design. The creative thinking skills enable students to generate hypotheses, to generate and extend ideas, to exercise their imagination and to seek innovative alternatives for solving problems [5]. Combining ideas can lead to "another way" of doing things, to the continuation of "the same way" of doing things or to ideas about "how not to continue" working that way [6-7].

\footnotetext{
* Corresponding author: claude.pyr@gmail.com
} 


\section{Encouraging the engineering students' creativity}

Case study - a group of 20 engineering students (group 1) using computer-aided design by means of Inventor program, attended six lectures on creativity, according to the following schedule: three lectures throughout 15 days, 7 days of pause, followed by the last three lectures during another 15 days. At the end of each lecture, the subjects solved a creativity test. At the end of each of the two periods, competitions were organized for the design of a piece having a high degree of complexity. The contestants were divided into two groups: one group consisting of 20 students randomly enrolled (group 2) and the group trained in creativity (group 1). The projects carried out by the creative students were much more elegant and more correctly performed, so the creative training can be associated not only to some behavioral changes but also to practical activities (see Figure 1).

The same method was applied by an automotive company to the students of an engineering faculty. In this case, students were required to come up with some variants of Electrical Discharge Machining (EDM) of some stamping molds needed for the performance of some bodywork elements. From the technical, economic and creative perspective, the results were significantly superior for the group that was trained in creativity (in this case the Group 3). The randomly created group was named Group 4. The comparative results are shown in Table 1.

Table 1. Comparative results

\begin{tabular}{|c|c|c|c|c|c|}
\hline $\begin{array}{c}\text { Criterion / } \\
\text { Group }\end{array}$ & $\begin{array}{c}\text { Execution } \\
\text { Time (T) }\end{array}$ & $\begin{array}{c}\text { Design } \\
\text { (D) }\end{array}$ & $\begin{array}{c}\text { Correctness } \\
\text { (C) }\end{array}$ & $\begin{array}{c}\text { Materials } \\
\text { Economy } \\
\text { (E) }\end{array}$ & $\begin{array}{c}\text { Novelty } \\
\text { Degree (N) }\end{array}$ \\
\hline Group 1 & 4 & 5 & 5 & 4 & 5 \\
\hline Group 2 & 2 & 3 & 3 & 4 & 4 \\
\hline Group 3 & 5 & 4 & 5 & 5 & 4 \\
\hline Group 4 & 3 & 3 & 3 & 4 & 4 \\
\hline
\end{tabular}

For each criterion taken into account, the grades from 1 to 5 were given as follows: 1 (poor), 2 (satisfactory), 3 (good), 4 (very good), 5 (excellent).

A code according to its name was assigned to each criterion: time-T, design-D, correctness-C, economy-E and novelty- $\mathrm{N}$. The evaluation of the creativity was performed by calculating the determinants of square matrices corresponding to the groups 1 and 2, 3 and 4 or 1 and 3 , leading to the diagram from Figure 2.

The evaluation of the creativity can be integrated into the chaos theory. Small fluctuations of the creativity will lead to different results in the engineering complex system. Their analysis will result in various conclusions on the use of creative education in higher technical education. The chaos equation would be simple if the students' creativity increased indefinitely, but the effect generated by individual resources, the quantity and quality of the accumulated education, make this equation incorrect [8].

The simplest equation, which takes into account the above factors, might be as follows:

$$
n c g_{1}=r \cdot n c g_{0}
$$

Where: $\mathrm{ncg}_{1}$ is the number of creative graduates in the next year; $\mathrm{ncg}_{0}$ - the number of creative graduates in the current year; $r$ - the growth rate, considered between 1 and 5 . 


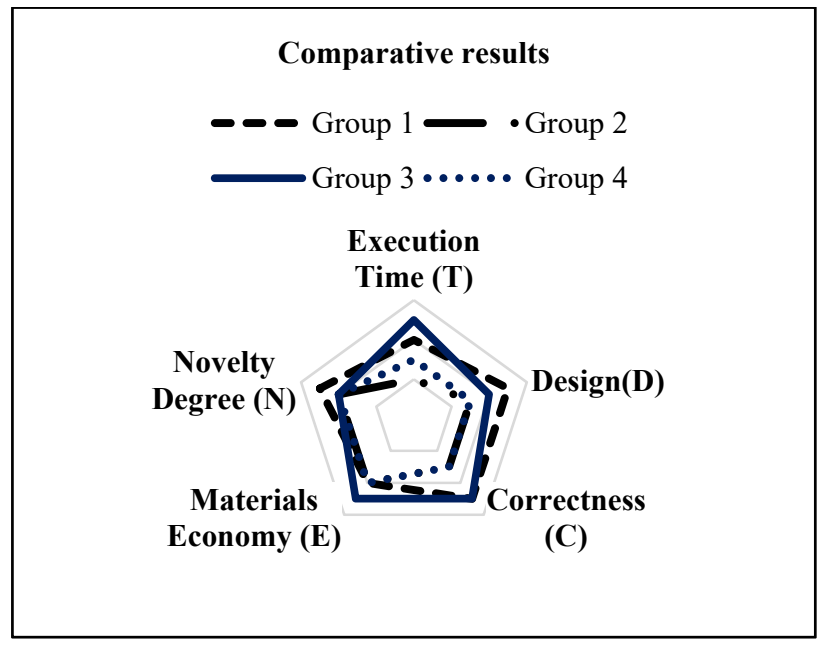

Fig. 1. Practical results of engineering creative education.

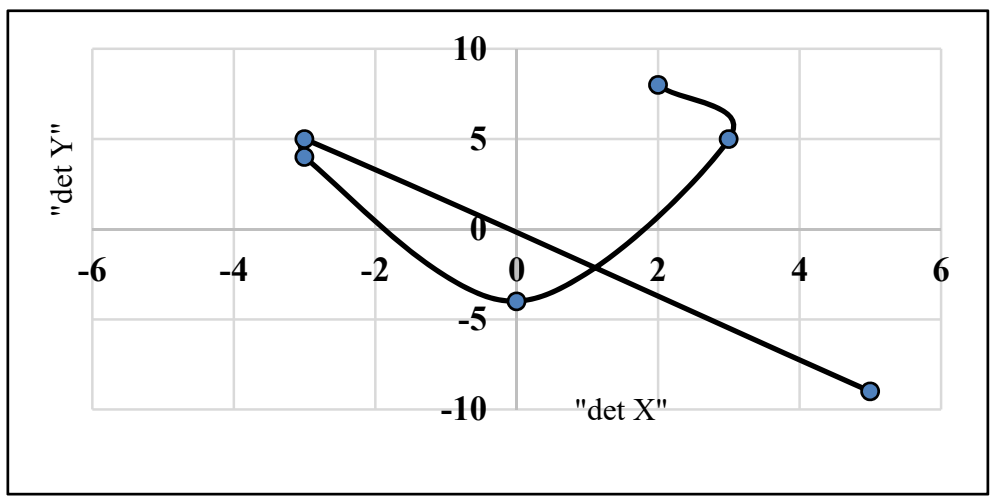

Fig. 2. Creativity Evaluation Diagram.

\section{Boosting the engineering students' intelligence and creativity with the aid of Image Streaming technique}

The use of Image Streaming technique based on creative thinking can have positive results, especially in the internships that students do in companies and organizations that perform engineering activities [9-10]. The stages required in this technique are as follows:

Stage 1 - expecting the completion of an internship of at least 7 days in order to increase the impact of the new activities and technologies on students. In this stage the accumulated personal factors such as knowledge, skills and attitudes lead to the development of the creativity.

Stage 2 - in a quiet office for 30 minutes maximum (this meeting can last between 10 and 30 minutes), each student describes aloud the reminded images (concentrating on the inner screen of the mind) related to a certain technological process (realizing that different frequencies of the thoughts received through the stream of consciousness is an "input" for the brain, as consciousness cannot be perceived as an object). The descriptions are recorded using any type of device that can record human voice (useful in stage 3). Subsequently, the thoughts are converted into electrical energy, which is amplified and sent to the central nervous 
system, so as the understanding phenomenon to take place. During the concentration process, along with images, other sensorial items may be involved such as: smell (examples: the smell of oil, coolant, dielectric fluid used in EDM etc.) or the noise specific to a particular processing activity. Focusing takes place in a complex of situational factors (attention, mood, motivation, reward etc.), with a significant impact on the creativity development process [11]. Thus, the evolution of an image description in conjunction with various other senses acquires a fluid nature (the description flows logically and coherently).

Stage 3 - during the seminar courses, each group of students listens to audio recordings and has discussions on specific topics of interest, developing methods of image decoding. The method is considered as a kind of "brainstorm" based on descriptions, not on ideas and answers, as in usual brainstorming, but with rules similar to this.

Stage 4 - the most important outcome of the discussions is the feedback, an element that stimulates intelligence and creativity. This technique is used both as a method to increase the creativity, as well as in order to acquire certain accelerated learning techniques. Since cloud technology replaces IT local systems, the data obtained are stored in the cloud, to be used in satellite or terrestrial analogue networks, particularly in best-effort IP digital networks (for example: Internet).

\section{Social Media, the innovation support of creative engineering education}

As result of our concern to analyze the way in which new IT technologies are perceived in the online environment, we collected tweets by streaming methods from July 10 to July 22, 2016 [12]. The used words flow was: "cloud computing, virtualization." The total number of collected tweets was 184,000 , of which only 79,752 have unique content, the difference being retweets. The collected data were grouped according to the criteria: General information on cloud computing (Table 2); Cloud Computing Providers (Table 3). For these collected data we determined statistical indicators on the calculation of means, synthetic position indicators and scattering indicators.

Table 2. General Cloud.

\begin{tabular}{|l|r|}
\hline $\begin{array}{c}\text { Words group searched in } \\
\text { tweets }\end{array}$ & $\begin{array}{c}\text { Number of } \\
\text { tweets }\end{array}$ \\
\hline Cloud Engineer & 223 \\
\hline Cloud Engineer jobs & 129 \\
\hline Cloud risk & 656 \\
\hline Cloud encrypted & 36 \\
\hline Cloud Developing & 21 \\
\hline Cloud- Machine Learning & 453 \\
\hline Cloud- virtualization & 430 \\
\hline \multicolumn{2}{|c|}{ Mean indicators } \\
\hline Arithmetic mean & 278.26 \\
\hline Harmonic mean & 74.71 \\
\hline Geometric mean & 160.79 \\
\hline \multicolumn{2}{|c|}{ Position indicators } \\
\hline Median & 223 \\
\hline \multicolumn{2}{|c|}{ Scattering indicators } \\
\hline Index of dispersion & 635 \\
\hline Standard deviation & 222.47 \\
\hline
\end{tabular}

Table 3. Cloud Providers.

\begin{tabular}{|l|r|}
\hline \multicolumn{1}{|c|}{$\begin{array}{c}\text { Words group searched in } \\
\text { tweets }\end{array}$} & $\begin{array}{c}\text { Number of } \\
\text { tweets }\end{array}$ \\
\hline Cloud IBM & 5368 \\
\hline Cloud Google & 6215 \\
\hline Cloud Amazon & 2373 \\
\hline Cloud Azure & 3679 \\
\hline Cloud Oracle & 3385 \\
\hline Cloud Microsoft & 9666 \\
\hline Google Microsoft Amazon & 630 \\
\hline \multicolumn{2}{|c|}{ Mean indicators } \\
\hline Arithmetic mean & 4473.71 \\
\hline Harmonic mean & 2312.83 \\
\hline Geometric mean & 3465.57 \\
\hline \multicolumn{2}{|c|}{ Position indicators } \\
\hline Median Scattering indicators \\
\hline \multicolumn{2}{|c|}{} \\
\hline Index of dispersion \\
\hline Standard deviation \\
\hline
\end{tabular}


Unless the set of numbers provided contains duplicates, the returned modal value is \# N/A. Cloud and virtualization are technologies that have been developed in order to reduce costs and maximize the use of IT resources.

Starting from the actual situation where virtualization can be achieved without cloud whereas cloud without virtualization is hardly doable - and analyzing the data in Table 2, we note that the "Cloud-virtualization" appears twice as much as the "Cloud Engineer" relationship.

Furthermore, the "Cloud Engineer" is twice more frequent than the "Cloud Engineer jobs" group. However, according to Figure 2 and the data in Table 2, the "Cloud risk" pair has priority in the analyzed tweets. The main cloud suppliers, according to analyzed data, are shown in Figure 3.

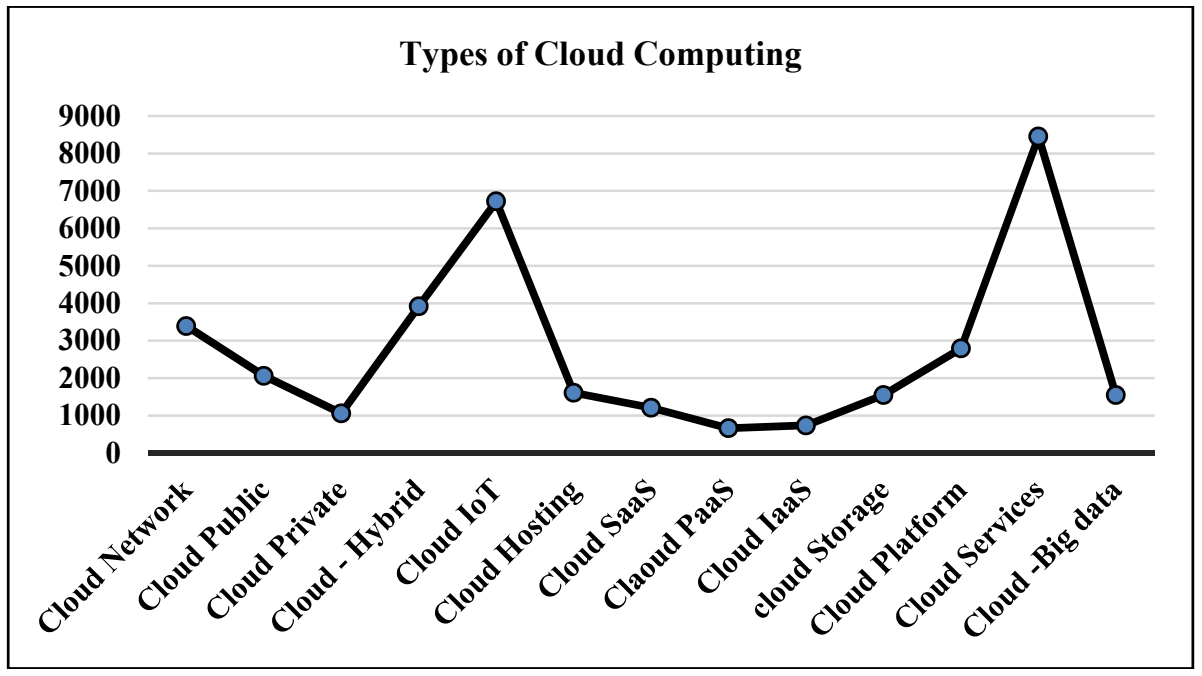

Fig. 3. Frequency of tweets pairs containing cloud.

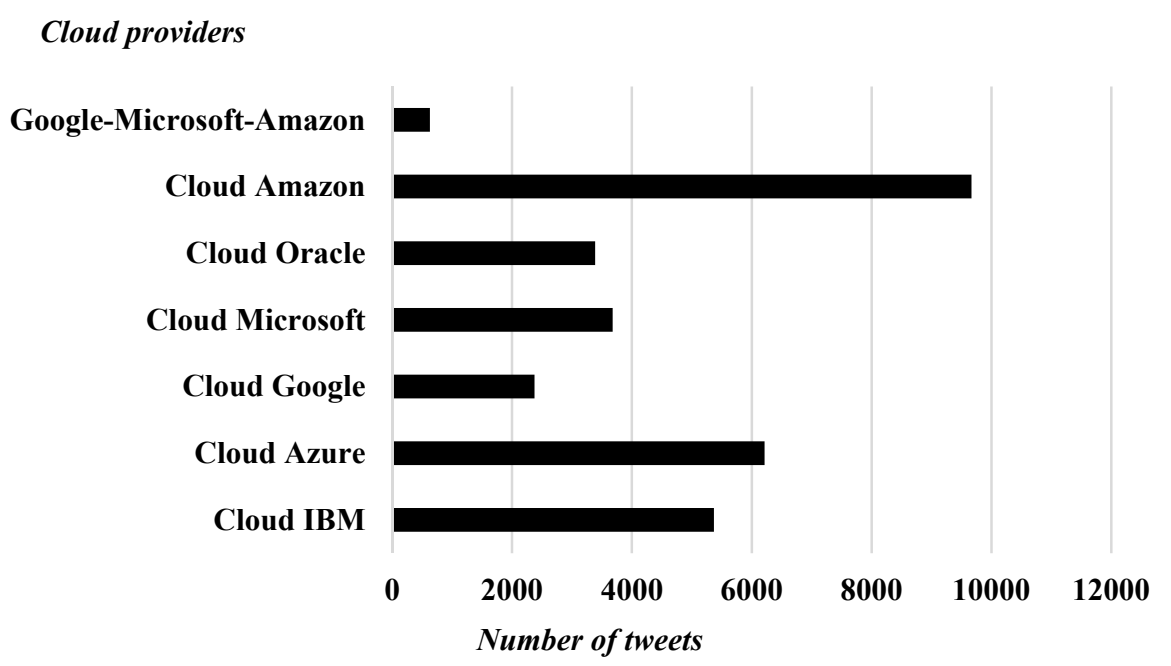

Fig. 4. Cloud provider's distribution. 
Researches financed through the projects: Joint Applied Research Project supported by MENUEFISCDI, project no. PN-II-PT-PCCA-2013-4-0236, Contract no. 222/2014.

\section{Conclusions}

Creativity and innovation are the most important drivers of the economic growth sustainability and the competitive achievements in knowledge-based economy. The engineering departments of the technical universities should develop new disciplines and programs to develop creativity, based on an original and valuable implementation of creativity increase techniques, providing practical solutions in order to include creativity in the engineering programs.

The activity of a cloud engineer through a creative and innovative action must be carried out in conjunction with the security elements and taking into account the risks the data in the cloud may be exposed to. At present there are technologies that revolve around cutting edge security platforms that protect the resources in the cloud.

The social media data can also be analyzed in terms of unconventional processing by means of ultrasounds in order to identify new specific knowledge. It is known that the involvement of those people, who are not part of the project team as they work in another field, tends to be more creative than that of those who worked for a long time in the same field.

Based on subsequent research, the results obtained by teams of students will be analyzed, following the above mentioned stages and implementing the possible solutions, relative to construction of the end part of ultrasonic horn, where the tool for ultrasonically aided electrical discharge machining is clamped, in the frame of the PN-II-PT-PCCA-2013-4-0236 project, "High productivity and precision technology and equipment for micro-electrical discharge machining aided by ultrasonic".

\section{References}

1. C.V. Doicin, S. Chircu, B.G. Coteț, M.E. Ulmeanu, M.S. Sălvan, AMM, 834, 5, (2016)

2. J.M. Eger, San Diego State University, (2012)

3. W. Sarkissian, D. Hurford, C. Wenman, Earthscan publishes in association with the International Institute for Environment and Development, London, UK, (2010)

4. I. Badran, EJEE, 32, Issue 5, 13, (2007)

5. B. Muirhead, IJITDL, 1, No. 12, (2004)

6. R.F. Verderber, D.D. Sellnow, K.S. Verderber, Student Edition. Cengage Learning, USA, 2, (2013)

7. N.P. Kirillov, E.G. Leontyeva, Y.A. Moisenko, International Conference of Research Paradigms Transformation in Social Sciences, Elsevier Ltd. (2015)

8. H.N. Teodorescu, IJGS, 41, No. 8, 20, (2012)

9. W. Wenger, Project Renaissance, Singapore, 2, (1992)

10. D. McKeag, School of Electrical and Mechanical Engineering, University of Ulster at Jordanstown, UK, (2008)

11. L.D. Ghiculescu, N.I. Marinescu, O. Alupei, N. Căruțașu, Key Engineering Materials, 651-653, 6, (2015)

12. C. Pirnau, M. Titu, L. Rosca, M. Pirnau, Proceeding The 2nd International Scientific Conference SAMRO 2016, "News, challenges and trends in management of knowledgebased organizations", Paltinis, Sibiu County, Romania, 8, (2016) 